\title{
PRINSIP DAN LANGKAH-LANGKAH PENERAPAN FOCUS GROUP DISCUSSION UNTUK MENINGKATKAN KETERAMPILAN BERBICARA DAN BERPIKIR KRITIS MAHASISWA
}

\author{
Marham Jupri Hadi ${ }^{1}$; Muh. Junaidi ${ }^{2}$ \\ ${ }^{1}$ Universitas Nahdlatul Wathan Mataram: marhamhadi@ gmail.com
}

\begin{abstract}
Artikel Info

\begin{tabular}{l}
\hline \\
Keywords: Focus \\
Group Discussion; \\
Critical Thinking; \\
Speaking Skills
\end{tabular}
\end{abstract}

\section{A. PENDAHULUAN}

Keterampilan berbicara merupakan satu dari empat keterampilan berbahasa yang perlu dimiliki oleh setiap individu agar mereka berhasil dalam mengkomunikasikan pemikirannya kepada orang lain secara efektif. Oleh karena itu diperlukan upaya untuk mengembangkan keterampilan tersebut khususnya dijenjang perguruan tinggi. Metode pengembangan keterampilan berbicara harus dilakukan secara integratif dengan keterampilan berbahasa lainnya seperti menyimak, menulis dan membaca karena keempat keterampilan makro tersebut saling berkaitan. Seperti yang telah dilakukan oleh Jassem (1997) untuk meningkatkan kemampuan mahasiswa program studi bahasa Inggris di Malasyia dengan mengintegrasikan tugas menulis dan seminar. Pada artikel ini kami akan mendeskripsikan hasil penelitian kami terkait pengembangan metode peningkatan keterampilan berbicara dan berpikir kritis melalui kegiatan Focus Group Discussion (FGD).

Dalam konteks pembelajaran bahasa Inggris di perguruan tinggi Indonesia, sering muncul pertanyaan kenapa mahasiswa program studi pendidikan atau sastra Inggris tidak mencapai kompetensi berbahasa yang sesuai dengan harapan. Salah satu penyebab utamanya adalah karena kurangnya rasa percaya terdiri atau munculnya rasa takut salah (Trent, 2009). Penyebab lainnya adalah kurangnya perhatian guru terhadap pengajaran berbicara secara eksplisit (Hodson, 2006). Bashirudin (2003) juga mengungkapkan bahwa faktor pemicu kurangnya kemampuan berbicara dalam bahasa Inggris disebabkan oleh tidak digunakannya bahasa Inggris sebagai bahasa komunikasi sehari-hari. Hal ini 
seringkali kita temukan dalam konteks pengajaran bahasa Inggris sebagai bahasa assing seperti Indonesia. Faktor lain yang juga terungkap pada penelitian sebelumnya berkaitan dengan kurangnya kemampuan bahasa Inggris guru atau pengajar serta pemilihan metode yang belum cocok untuk memicu terjadi pembelajaran berbicara yang efektif.

Speaking skill atau kemampuan berbicara merupakan kemampuan yang paling sering digunakan oleh pembelajar atau pengguna bahasa, khususnya bahasa Inggris. Burns and Joyce (1997) menjelaskan bahwa berbicara merupakan proses interaktif untuk mengkonstruksi makna yang melibatkan aktifitas menghasilkan, menerima dan mengolah informasi, dan prosesya seringkali spontan, terbuka, berkembang dan seringkali tidak bisa diprediksi.Bagi kebanyakan pembelajar bahasa Inggris mereka mengalami banyak kendala yang seringkali disebabkan oleh banyak faktor.Satu diantara faktor yang paling dominan adalah faktor psikologi seperti merasa takut membuat kesalahan, malu, frustasi serta grogi (Haidara, 2014).

Beberapa penelitian telah dilakukan untuk menigkatkan kemampuan berbicara para pembelajar bahasa Inggris di Indonesia. Salah satunya adalah dengan menggunakan kegiatan membaca cerita pendek secara lisan (Khosravani dan Khoosf, 2014). Penelitian mereka membuktikan bahwa bercerita mampu meningkatkan kemandirian siswa dalam belajar bahasa asing serta meningkatkan kemampun beerbicara. Penelitian terkini (Elnadeef dan Abdala, 2019) terkait upaya peningkatan kemampuan berbicara dalam bahasa inggris adalah melalui English Club. Hasil penelitiannya menunjukkan bahwa English club memberikan ruang kepada mahasiswa untuk berkomunikasi secara lebih santai, terbebas dari ketakutan berkomunikasi serta meningkatkan kemampuan berpikir kritis dan berbicara.

Terdapat variasi definisi yang berkembang terkait konsep dari berpikir kritis. Beberapa diantaranya adalah Tama (1989) dan Eggen (2012).Tama (1989) mendefinisikan berpikir kritis sebagai cara berpikir membenarkan keyakninan seseorang dan tidak akan terpengeruh oleh argumen orang lain kecuali argumen tersebut meyakinkanya. Definisi yang lebih singkat tentang berpikir kritis digagas oleh Eggen (2012) dimana berpikir kritis adalah kemampuan dan kecenderungan untuk membuat dan melakukan penilaian pada ringkasan berdasarkan bukti. Kemampuan berpikir kritis selanjutnya diartikan sebagai kemampuan untuk berpikir logis, sistematis, produktif, dan reflektif sebagai dasar untuk membuat pertimbangan dan pengambilan keputusan yang baik (Hidayah, 2017).

Implementasi konsep berpikir kritis tidak serta merta diterima dalam kultur yang berbeda karena ada anggapan bahwa konsep yang lahir dari barat ini bisa berbenturan dengan nilai kearifan lokal yang ada di wilayah timur. Misalnya, mengkiritisi pendapat yang berbeda khususnya yang berasal dari orang tua atau dituakan misalnya tokoh masyarakat dan guru merupakan hal yang tabu.Hal ini menjadi tantangan tersendiri untuk menerapkan konsep berpikir kritis dalam konteks pendidikan tinggi Indonesia.Bahkan ada keraguan apakah konsep berpikir kritis bisa diadopsi dalam pembelajaran karena mengajarkan konsep ini kepada nonnative speakers akan berbenturan dengan masalah budaya (Atkinson, 1997). Oleh karena itu Atkinson menyarankan agar guru atau instruktur bahasa harus lebih hatihati untuk mengajarkan konsep berpikir kritis kepada para peserta didiiknya.Untuk keperluan pembelajaran bahasa Inggris (khususnya di program studi pendidikan bahasa Inggris) Davidson

(1998) 
menyarankan agar konsep berfikir kritis perlu didefinikasi secara jelas dan disesuaikan dengan kearifan lokal yang ada di lingkungan perguruan tinggi.

\section{Focus Group Discussion (FGD)} merupakan bentuk wawancara terhadap satu kelompok dimana pewawancara lebih berperan sebagai moderator dari diskusi tersebut, bukan semata-mata jadi penanya.FGD bisa diandalkan untuk menggali informasi tentang orang berserta pengalamannya, motivasi, perilaku, kebutuhan dan aspirasi mereka (Brunt, 1997). Dengan demikian FGD berpotensi untuk memberikan peluang dan ruang lebih luas kepada para peserta diskusi dalam hal ini mahasiswa untuk mengembangkan kemampuan mereka berkomunikasi sekaligus merangsang kemampuan menganalisa mereka terkait topik yang menjadi fokus pembahasan bersama.Senada dengan itu, Gokhale (1995) berpendapat bahwa saling bertukar ide dalam kelompok kecil merupakan salah satu perilaku utama yang bisa merangsang kemampuan berpikir kritis. Hal ini terjadi karena percakapan diantara para mahasiswa akan memicu proses berpikir sekaligus aktifitas berkolaborasi tersebut (Ronald A. Styron, 2014).

\section{B. METODE PENELITIAN \\ Design Based Research (DBR)}

Penelitian ini bertujuan untuk 1) menghasilkan rancangan FGD sebagai metode untuk meningkatkan kemampuan berbicara dan berpikir kritis mahasiswa. Berkenaan dengan tujuan tersebut, maka penelitian ini mengadopsi Design Based Research (DBR) yakni sebuah metode penelitian yang sistematis, namun fleksible, yang bertujuan untuk meningkatkan praktik pendidikan melalui kegiatan analisa iterative, perancangan, pengembangan, penerapan, yang dilaksakan secara kolaboratif oleh peneliti dan pengajar dalam real-wrord setting dan berdampak pada lahirnya prinsip dan teori pembelajaran yang peka terhadap konteks (Wang and Hannafin, 2005). DBR digunakan untuk memahami bagaimana, kapan dan mengapa sebuah inovasi pembelajaran berhasil dan tidak semata-mata untuk mengukur efektifitas sebuah inovasi pembelajaran sebagaimana yang umumnya terjadi pada penelitian eksperimen atau dalam bentuk penelitian tindakan. Pada penelitian ini, kami mengadopsi tahapan DBR yang dirumuskan oleh Reeves (2016) sebagaimana tergambar pada diagram berikut:

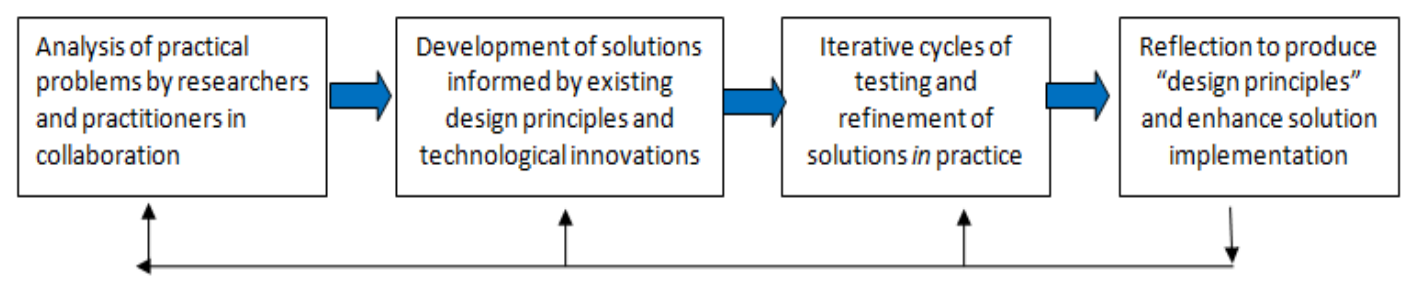

Gambar 1. Design-Based Research (diadaptasi dari Reeves (2006: 59)

\section{Partisipan, Jenis, Metode Pengumpulan dan Analisa Data}

Penelitian ini akan melibatkan 5-8 mahasiswa sebagai partisipan penelitian yang dipilih menggunakan purposive sampling technique. Adapun jenis data yang dikumpulkan terdiri dari tiga jenis data. Pertama adalah data yang berhubungan dengan rancangan FGD seperti capaian pembelajaran (Learning Outcomes) dengan 
FGD, materi, dan rencana pembelajaran. Data kedua berupa video pembelajaran, data hasil observasi, serta masukan dari tim pengajarpeneliti dan peserta. Data ketiga dalam bentuk dokumen refleksi peserta FGD dan pengajar (diaries) serta transkrip FGD. Data yang tersebut selanjutnya dianalisa dengan menggunakan thematic analysis, yakni proses mengidentifikasi tema dari data kualitatif dengan menggunakan Microsoft Excel sebagai instrumen analisa (Bree \& Gallagher, 2016). Braun \& Clarke (2006) merumuskan 6 tahap untuk melakukan analisa tematik sebagaimana tergambar dalam diagram berikut:

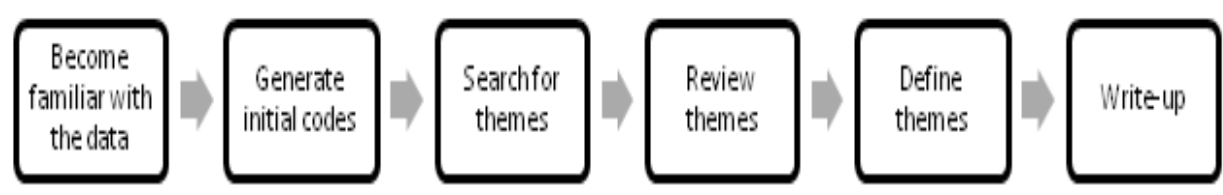

Gambar 2. Tahapan Analis Tematik (Braun \& Clarke, 2006)

\section{Peran Peneliti}

Pada penelitian ini, kami berperan sebagai peneliti sekaligus pengajar. Sebagai peneliti, kami berperan untuk melakukan kajian literatur terkait rancangan metode pembelajaran yang akan kami terapkan dalam rangka meningkatkan kemampuan berbicara dan keterampilan berpikir kritis mahasiswa. Sebagai pengajar, kami secara kolaboratif merancang FGD sebagai metode pembelajaran, kemudian menerapkan dan memperbaiki desain FGD dalam beberapa siklus. Pada tahap akhir, tim peneliti akan melakukan refleksi secara kolaboratif dengan para peserta untuk mengidentifikasi prinsipprinsip perancangan FGD sebagai solusi untuk meningkatkan kemampuan berbicara dan berpikir kritis.

\section{HASIL DAN PEMBAHASAN}

\section{Model dan Prinsip Desain FGD untuk meningkatkan kemampuan berbicara dan berpikir kritis}

Tujuan dari penelitian ini adalah untuk menghasilkan prinsip-prinsip dalam desain
FGD sebagai satu metode pembelajaran bahasa Inggris di perguruan tinggi untuk meningkatkan kemampuan berbicara dan bepikir kritis. Prinsip desain yang direkomendasikan pada penelitian ini merupkan adaptasi dari berbagai best practice $F G D$ dalam berbagai bidang sekaligus merupakan hasil refleksi dan perbaikan secara iterative dalam setiap siklus FGD.

Hamzah dan Ting (2010) bahwa kerja kelompok, seperti FGD, memiliki dampak pedagogis yang signifikan dan sangat praktis untuk diterapkan jika dipersiapkan dengan baik, terutama untuk meningkatkan kemampuan berbicara dan berpikir kritis. Berdasarkan hasil refleksi pada setiap siklus FGD yang kami lakukan bersama para peserta dan fasilitator, kami mengidentifkasi beberapa prinsip-prinsip yang bisa mengoptimalkan implementasi FGD dalam rangka meningkatkan kemampuan berbicara serta keterampilan berpikir kritis. Model dan Prinsip-prinsip tersebut adalah sebagai berikut: 


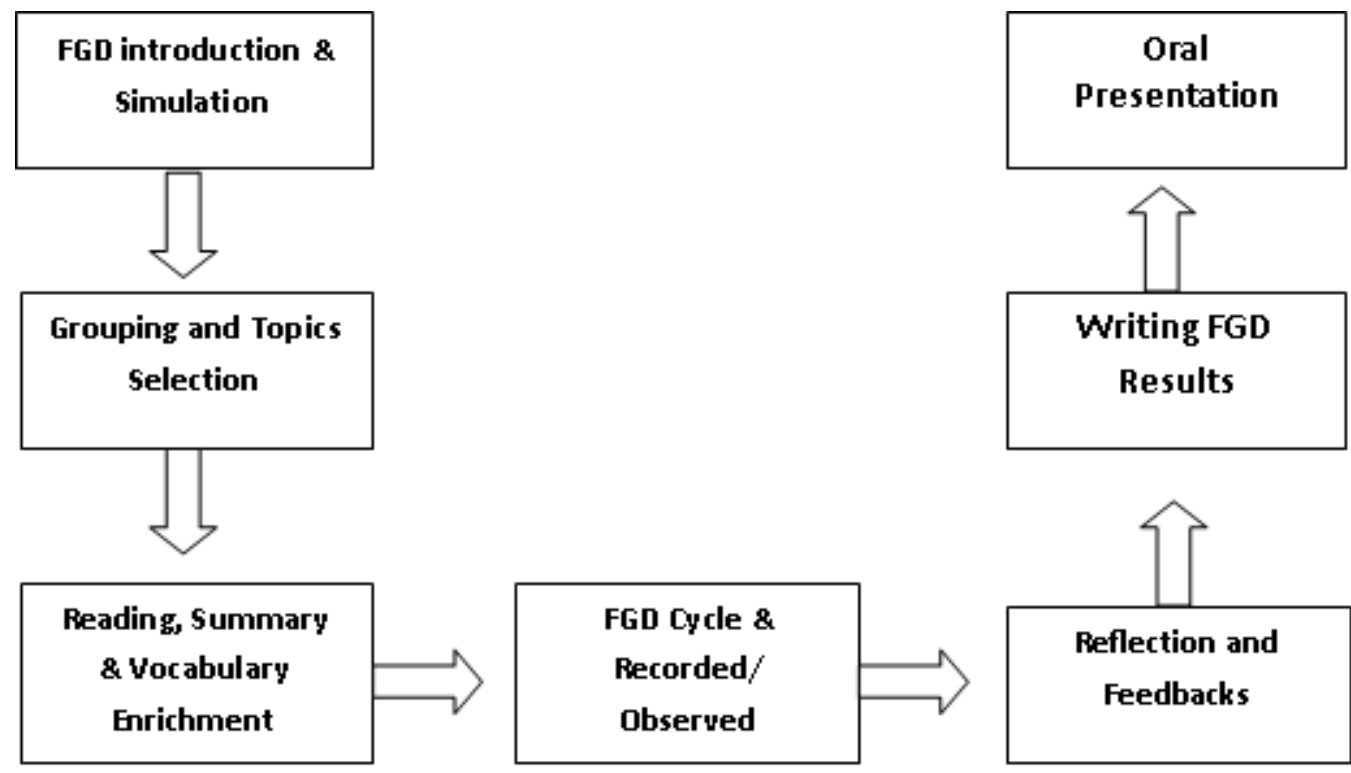

Gambar 3 Bagan Alir Pembelajarann Speaking \& Critical Thinking dengan FGD

\section{Introduction and Simulation}

Pertama, sebelum FGD diterapkan, Dosen perlu mengenalkan konsep FGD kepada para peserta. Hal ini bertujuan untuk memberikan gambaran bagaimana FGD sebaiknya dilakukan. Pada penelitian ini, upaya pengenalan FGD kepada peserta FGD melibatkan seorang praktisi LSM yang selama ini bergelut dengan kegiatan FGD di masyarakat. Selain mendapatkan gambaran teoritis peserta juga mendapatkan cerita sukses dari FGD di lapangan. Untuk memperkuat serta menambah pemahaman tentang FGD kepada peserta, kami juga menayangkan beberapa video yang mencontohkan praktik FGD. Hal tersebut menjadikan pembelajaran lebih kaya dan tidak monoton serta didominasi oleh dosen karena menggunakan pendekatan multi sources learning. Setelah konsep FGD dikenalkan maka peserta FGD dilibatkan dalam kegiatan simulai bersama Fasilitator terlatih, dalam hal ini dosen. Simulasi FGD dilakukan selama beberapa kali dalam rangka untuk menerapkan konsep-konsep yang telah didapatkan dari pakar dan video tersebut.

\section{Group and Iopic Selection}

Ketiga, membagi kelas menjadi beberapa kelompok kecil (maksimal 10 orang) dimana komposisi masing-masing kelompok terdiri dari peserta dengan karakter dan kemampuan yang bervariasi. Hal ini bertujuan agar FGD menjadi lebih berwarna dan lebih banyak lagi variasi ide yang akan terungkap ke permukaan. Alasan lain kenapa jumlah peserta FGD harus tetap kecil adalah untuk memastikan bahwa semua peserta memiliki kesempatan yang lebih banyak untuk mengungkapkan ide dan pemikiran mereka. Tetapi, dalam kasus kelas yang besar dimana kelas akan terbagi menjadi beberapa kelompok, dosen perlu menyisakan beberapa orang di luar kelompok-kelompok tersebut yang difungsikan untuk mengobservasi (peer observations) bahkan mengontrol jalannya FGD. Peer observation sangat bermanfaat untuk mendukung agar terjadi komunikasi riil dan melatih kemampuan peserta menjadi pendengar aktif dan efektif (Venema, 2006). Hal ini bertujuan untuk memastikan bahwa FGD berjalan sesuai dengan yang seharusnya. Jika jumlah kelas sedikit maka peran observer dan control bisa dilakukan oleh dosen. 
Setelah group terbagi, maka kita perlu memprtimbangkan topik-topik apa saja yang akan menjadi fokus dari diskusi mereka. Berkenaan dengan itu Guendouzi (2016) menyarankan agar topik-topik yang digunakan dalam diskusi adalah yang mampu memicu lahirnya pemikir kritis karena topic-topik tersebut bisa meningkatkan kemampuan berbicara. Selain itu, kita juga perlu mempertimbangkan topic-topik yang berkaitan dengan kehidupan sehari-hari peserta FGD, karena latihan menyimak dan berbicara tentang topik topik terserbut dapat meningkatkan rasa percaya diri peserta diskusi (Songsiri, 2017).

Sebelum FGD juga fasilitator perlu mendisktribusikan topik FGD beserta pertanyaannya kepada peserta FGD beberapa hari sebelum FGD dilakukan agar peserta FGD memiliki kesempatan untuk menggali informasi terkait topik yang akan di diskusikan. Pengalaman ketika meminta peserta FGD untuk mencari FGD beberapa menit sebelum FGD menunjukkan bahwa hal tersebut kurang efektif meskipun mereka diminta untuk mencari referensi di internet. Memberikan kesempatan membaca kepada peserta FGD bisa dilakukan agar peserta FGD menjadi lebih memahami topic yang akan dibahas. Namun, cara terbaik untuk mendapatkan jawaban yang banyak terkait topik FGD adalah dengan membuat peserta FGD berasal dari orang yang memiliki latar belakang yang berbeda-beda.

Fasilitator FGD perlu menyiapkan pertanyaan-pertanyaan terbuka sebelum FGD dilakukan dengan tujuan untuk memandu arah diskusi. Pertanyaan juga akan menjadi pemicu peserta untuk berpikir dan mencari jawaban. Hasil pemikiran atau jawaban tersebut kemudian akan menjadi isi dari diskusi. Dari beberapa kali FGD, kami memperhatikan bahwa pertanyaan yang menjadi penentu apakah peserta akan berbicara atau tidak. Jika pertanyaan FGD bersifat tertutup dengan pertanyaan "apakah", maka kemungkinan besar peserta akan memberikan tanggapan dalam bentuk "ya dan tidak". Hal ini menunjukkan bahwa penggalian tentang sub-sub topik dalam bentuk pertanyaan harus dilakukan sebelum diskusi dimulai agar peserta mengerti informasi apa yang diminta untuk disampaikan dalam forum diskusi tersebut.

\section{Role of facilitator}

Kesuksesan diskusi sangat ditentukan oleh bagaimana seorang fasilitator memainkan perannya. Untuk keperluan pembelajaran, tidak saja berperan untuk memfasilitasi diskusi, tetapi juga mengontrol agar FGD bisa berjalan secara kondusif. Oleh karena itu, fasilitator perlu mengingatkan peserta FGD untuk menghindari terjadinya debat karena debat bisa menutup peluang lahirnya information sharing. Perlu ditekankan juga bahwa orientasi dari FGD bukanlah mencari pandangan yang benar atau salah, tetapi lebih kepada untuk menggali pandangan yang berbeda sebanyak mungkin atau pengalaman hidup semua peserta FGD terkait topik atau permasalahan yang sedang didiskusikan. Hal ini terungkap dari refleksi fasilitator FGD pada riset ini.

Hal lain yang perlu diingat adalah seringkali diskusi mengalami kebuntuan. Untuk merespon situasi tersebut, fasilitator atau dosen perlu membantu memberikan stimulus atau pertanyaan yang memancing. Pertanyaan lanjutan (follow-up questions) tersebut diperlukan untuk menghidupkan FGD kembali. Sebagaimana yang diungkapkan oleh Fasilitator FGD pada penelitian ini bahwa keberhasilan FGD terletak pada fasilitator. Fasilitator harus memantau semua peserta agar bisa berkontribusi secara aktif.

"Intinya dalam FGD, kita jangan sampai berdebat. Kemudian kita berusaha menurunkan ego kita masingmasing dan tidak menganggap jawaban kita adalah yang paling baik karena FGD pada hakikatnya adalah mencari 
solusi bersama atas suatu

permasalahan yang sedang terjadi"

Hal lain yang kami temukan sangat bermanfaat untuk meningkatkan partisipasi peserta FGD adalah pemberian motivasi kepada mereka. Motivasi tidak hanya berperan untuk menggugah semangat belajar, tetapi juga akan mengalahkan rasa malu dan kurang percaya diri untuk berpendapat di depan publik. Peserta perlu diyakinkan bahwa setiap kata yang mereka ucapkan adalah nilai tambah bagi peserta lainnya dan setiap kali mereka memberikan pendapat (dalam bahasa Inggris khususnya) kepercayaan diri mereka akan meningkat.

\section{Adult Learning Strategy}

Prinsip kelima adalah FGD mengadopsi prinsip pembelajaran orang dewasa, (adult learning strategy), dimana fasilitator atau dosen memfungsikan diri sebagai mediator sebuah diskusi, bukan sebagai presenter. Jika Dosen memerankan diri menjadi presenter maka yang terjadi adalah diskusi akan didominasi oleh dosen dan akhirnya kebanyakan peserta akan menjadi pendengar. Berbeda dengan fasilitator yang berperan untuk mengajukan pertanyaan serta merangsang munculnya berbagai pendapat dari peserta FGD.

Pada penelitian ini juga kami mengidentifikasi beberapa rekomendasi agar peserta FGD bisa lebih optimal untuk berbicara dalam FGD, khususnya yang enggunakan bahasa Inggris. Kami menyimpulkan bahwa sebagian besar peserta memiliki kendala untuk berdiskusi full in English yang disebabkan oleh keterbatasaan kosakata serta penggunaan ungkapan-ungkapan yang umum dipakai untuk berpendapat seperti memulai pendapat, mengembangkan ide, menyatakan persetujuan serta menarik kesimpulan. Oleh karena itu, pada tahap-tahap awal, tidak masalah jika para peserta melakukan diskusi dengan metode mixed language (mencampur bahasa Indonesia dengan bahasa Inggris). Hal ini bertujuan agar kesempatan mereka untuk mengungkapkan ide-ide mereka tidak hilang disebabkan oleh kendala bahasa. Ketika itu terjadi, maka fasilitator perlu membuat catatan tentang hal tersebut untuk selanjutnya menjadi bahan masukan selesai FGD.

\section{Providing Feedbacks - Expressions and Phrases}

Langkah lain adalah dengan memberikan contoh-contoh ungkapanungkapan yang umum dipakai dalam diskusi seperti cara memberikan pendapat, merespon pendapat, serta mengembangkan ide dan mengambil kesimpulan. Rekomendasi lain ialah agar fasilitator perlu mengurangi beban psikologis peserta FGD, khususnya yang terkait dengan grammar. Fasilitator tersebut juga perlu menekankan agar para peserta tidak terfokus dengan grammar, vocabulary atau bahkan pronunciation. Hal ini bertujuan untuk memotivasi mereka untuk berbicara serta mengurangi rasa malu dan takut untuk salah, dua faktor yang seringkali membungkam peserta diskusi. Penelitian lebih lanjut tentang manfaat feedbacks kepada peserta FGD perlu dilakukan

\section{KESIMPULAN}

Pada penelitian ini juga kami mengidentifikasi beberapa prinsip-prinsip penerapan FGD dalam rangka mengingkatkan kemampuan berbicara serta keterampilan berpikir kritis. Prinsip-prinsip terintegrasi dalam desain pembelajaran yang ditawarkan pada penelitian ini yang meliputi: (1) pengenalan dan simulasi FGD, (2) penentuan kelompok dan penyiapan topik FGD, (3) penggalian informasi dan peningkatan kosakata melalui kegiatan membaca, (4) praktik FGD, (5) refleksi dan pemberian masukan, 6) membuat catatan FGD, dan 7) presentasi lisan. Prinsip-prinsip implementasi tersebut bisa dimodifikasi sesuai dengan kondisi di masing-masing konteks pembelajaran. Akhirnya, temuan 
penelitian ini mungkin tidak sepenuhnya bisa direplikasi ke konteks lain, dan digeneralisasikan karena partisipannya hanya sedikit. Studi di masa mendatang diharapkan dapat memperluas penggunaan FGD dalam lingkup yang lebih luas untuk menilai efektivitasnya.

\section{Ucapan Terima Kasih}

Penelitian ini bisa terlaksana dengan dukungan pendanaan dari Kementrian Pendidikan dan Kebudayaan serta partisipasi dosen dan mahasiswa program studi Sastra dan Pendidikan Bahasa Inggris Universitas Nahdlatul Wathan Mataram.

\section{Daftar Pustaka}

Atkinson, D. (1997). A critical approach to critical thinking in TESOL.TESOL Quarterly, 31 (1):79-95

Bashiruddin, A. (2003). Learning English and learning to teach English: the case of two teachers of English in Pakistan. Unpublished doctorate dissertation, University of Toronto, Canada.

Boonkit, K. (2010) Enhancing the development of speaking skills for nonnative speakers of English. Procedia Social and Behavioral Sciences 2 (2010) 1305-1309

Braun, V. \& Clarke, V. (2006). Using thematic analysis in psychology. Qualitative Research in Psychology, 3, 77-101

Bree, R. \& Gallagher, G. (2016). Using Microsoft Excel to code and thematically analyse qualitative data: a simple, cost-effective approach. All Ireland Journal of Teaching and Learning in Higher Education (AISHEJ), 8(2), 2811-28114

Brewer, E.W (1997) 13 Proven Ways to Get you Messages Across: The Essential References for Teachers, Trainers, Presenters, and Speakers.Corwin Press Inc. Thousand Oaks, California
Brown, D, H. 2001. Teaching by Principles:An Interactive Approach to Language Pedagogy. (Second Edition). New York: Addison Wesly Longman Inc.

Brunt, P. (1997).Market research in travel and tourism.Oxford ;Boston: Butterworth-Heinemann

Burns, A. \& Joyce, H. (1997).Focus on speaking. Sydney: National Center for English

Language Teaching and Research

Crawford, A., Saul, W., Mathews, S. R., \& Makinster, J. (2005). Teaching and Learning Strategies for the Thinking Strategies. New York: The International Debate Education Association.

Davidson, B.W. (1998). A case for critical thinking in the English language classroom.TESOL quarterly, 32 (1):119-123

Design-Based Research: An Emerging Paradigm for Educational Inquiry. (2003). Educational Researcher, 32(1), 5-8.

https://doi.org/10.3102/0013189X0320 01005

Eggen, P and Kauchak, D. (2012).Strategies and Models for Teachers: Teaching Content and Thinking Skills. USA: Pearson Education, inc.

Elnadeef, E.I.E. dan Abdala, A.H.E.H (2019) The Effectiveness of English Club as Free Voluntary Speaking Activity Strategy inFostering Speaking Skill in Saudi Arabia Context. International Journal of Linguistics, Literature and Translation (IJLLT).IJLLT 2(1):230235

Fauzi, I. (2017) Improving Students' Speaking Ability through Small Group Discussion. Vol. 2, No. 2, 2017, 130138, DOI: 10.22236/JER_Vol2Issue2

Gokhale, A. A. (1995). Collaborative LearningEnhances Critical Thinking. 
Journal

of

Technology Education, 7(1). Retrieved from

http://scholar.lib.vt.edu/ejournals/JTE/ v7/gokhale.jet-v7n1.html

Guendouzi, R. (2016) Promoting Critical Thinking Topics To Enhance Efl Learners'speaking Skill: Beliefs And Perspectives. Disertasi pada Master of Art, University of Bejaia

Haidara, $Y$ (2014) Psychological Factor Affecting

English

SpeakingPerformance for The English Learners in Indonesia. Proceeding International Conferenceo on Educational Research And Evaluation (ICERE) 2014.Hal. 512-519

Hamzah, Mohd Hilmi and Lu, Yee Ting (2010) Teaching Speaking Skills Through Group Work Activities: A Case Study In SMK Damai Jaya. Teaching Speaking Skills Through Group Work Activities: A Case Study In Smk Damai Jaya . pp. 1-6. (Unpublished) Diakses dari http://eprints.utm.my/id/eprint/10255/

Hidayah, R., Salimi, M., \& Susiani, T. (2017).Critical Thinking Skill: Konsep Dan Inidikator

Penilaian. Taman Cendekia: Jurnal Pendidikan Ke-SD-an, 1(2), 127-133. doi:http://dx.doi.org/10.30738/tc.v1i2. 1945

Hodson, P. (2006). Listening to children's voices: unlocking speaking and listening in the primary classroom. In J, Deborah \& H, Pamela (Eds.) unlocking speaking and listening. Great Britain: David Fulton. Pp.1-16.

Khosravani, M. dan Khoosf, S.G. (2014) Fostering Efl Learners' Speaking and Listening Skills Via Oral Activities af Reading Short Stories. International Journal of Language Learning and Applied Linguistics World (IJLLALW)Volume 5 (1), January 2014; 329-337
Jassem, Z. A. (1997). Towards better speaking in the English class: A sociolinguistic approach. The English Teacher, XXIV, 41-52.

Nunan, D. (1997). Practical English language teaching. New York: McGraw Hill

Reeves, T. C. (2006) Design research from a technology perspective. In J. van den Akker, K. Gravemeijer, S. McKenney \& N. Nieveen (eds.), Educational design research. London: Routledge, 52-66

Ronald A. Styron, Jr., (2014) Critical Thinking and Collaboration: A Strategy to Enhance Student Learning. Systemics, Cybernetics and Informatics Volume 12 - Number 7 - Year 2014

Songsiri, M. (2007). An action research study of promoting students' confidence in speaking English. (Dissertation of Doctor of Education Degree), School of Arts, Education and Human Development, Victoria University, Australia. Diakses dari eprints.vu.edu.au/1492/1/Songsiri.pdep rints.vu.edu.au/1492/1/Songsiri.pd

S. Menggo, Seken, Ketut, Ratminingsih, Made (2013) The Effect Of Discussion Technique 